\section{(1)}

CrossMark

\title{
To stress or not to stress? Exercise pulmonary haemodynamic testing in systemic sclerosis
}

\author{
Edmund M.T. Lau ${ }^{1,2}$, Vivek Thakkar ${ }^{3,4}$, Marc Humbert $\circledast^{5,6,7}$ and Philippe Herve ${ }^{8}$ \\ Affiliations: 'Sydney Medical School, University of Sydney, Sydney, Australia. ${ }^{2}$ Dept of Respiratory Medicine, \\ Royal Prince Alfred Hospital, Camperdown, Australia. ${ }^{3}$ Dept of Rheumatology, Liverpool Hospital, Sydney, \\ Australia. ${ }^{4}$ School of Medicine, Western Sydney University, Campbelltown, Australia. ${ }^{5}$ Univ. Paris-Sud, \\ Université Paris-Saclay, Le Kremlin-Bicêtre, France. 'Service de Pneumologie, Hôpital Bicêtre, Assistance \\ Publique Hôpitaux de Paris, Le Kremlin-Bicêtre, France. ${ }^{7}$ INSERM UMR S 999, Hôpital Marie Lannelongue, \\ Le Plessis Robinson, France. ${ }^{8}$ AP-HP, Service de Pneumologie, Centre de Référence de l'Hypertension \\ Pulmonaire Sévère, DHU Thorax Innovation, Hôpital Bicêtre, Le Kremlin-Bicêtre, France.
}

Correspondence: Edmund M.T. Lau, Dept of Respiratory Medicine, Royal Prince Alfred Hospital, Missenden Road, Camperdown, NSW 2050, Australia. E-mail: edmund.laudsydney.edu.au

0 @ERSpublications

Exercise pulmonary hypertension may have prognostic significance in patients with systemic sclerosis http://ow.ly/qkpx304uPZE

Pulmonary arterial hypertension (PAH) is a leading cause of morbidity and mortality in systemic sclerosis (SSc) [1], and patients have a $\sim 10 \%$ lifetime risk of developing this devastating complication [2]. Despite targeted PAH therapy, outcomes of SSc-associated PAH (SSc-PAH) remain unsatisfactory, with a median survival of only 3-4 years from time of diagnosis $[3,4]$. In the hope of further improving outcomes in SSc-PAH, early disease detection has been a major focus of research in the past decade [5-9]. One important and highly debated topic is the utility of exercise pulmonary haemodynamic testing for the early diagnosis of pulmonary vascular disease [10-12].

From a physiological viewpoint, exercise stress testing for the unmasking of early or silent pathology appears a worthwhile pursuit. The pulmonary circulation is unique in that $>60 \%$ of its circulation must be obstructed before the resting mean pulmonary artery pressure (mPAP) rises above $25 \mathrm{mmHg}$ [13], a value which represents the consensus threshold for the diagnosis of pulmonary hypertension (PH) [14]. Thus, there is the potential that clinically important pulmonary vascular disease is left undiagnosed using the current diagnostic criterion. Reliance on resting measurements may be very specific, but is perhaps not sensitive enough for the early diagnosis of pulmonary vascular disease. Furthermore, there is also now ample evidence to support that patients with normal resting mPAP but an abnormal pulmonary haemodynamic response during exercise (also known as exercise $\mathrm{PH}$ ) develop symptoms of exertional dyspnoea [15-18]. So why do some experts remain circumspect or even oppose the concept of exercise haemodynamics testing of the pulmonary circulation?

Many readers will know that exercise haemodynamics were part of the definition of $\mathrm{PH}$ (exercise mPAP $>30 \mathrm{mmHg}$ ) until this was officially abandoned during the Fourth World Symposium on PH (Dana Point, USA, 2008) [19] due to uncertainties regarding the upper limits of normal exercise mPAP [20]. Exercise mPAP is also dependent on age, exercise type and exercise intensity [20]. A fundamental problem of the old definition of exercise PH was related to the fact that mPAP is a flow-dependent variable. Therefore, exercise mPAP must be adjusted for cardiac output in order to avoid false positive diagnoses of exercise $\mathrm{PH}$ [21], where elevated mPAP is simply driven by large cardiac output increases during exercise (as would occur in athletic individuals). To address this issue, new data have been accumulated in recent years and

Received: Sept 122016 | Accepted: Sept 152016

Conflict of interest: Disclosures can be found alongside this article at erj.ersjournals.com

Copyright @ERS 2016 
there is now broad agreement that a normal subject should not exceed an mPAP $>30 \mathrm{mmHg}$ and an $\mathrm{mPAP} /$ cardiac output ratio (total pulmonary resistance, TPR) $>3 \mathrm{WU}$ during exercise $[22,23]$. Therefore, the combination of $\mathrm{mPAP}>30 \mathrm{mmHg}$ and $\mathrm{TPR}>3 \mathrm{WU}$ has been proposed by various authors as a suitable "interim" definition of exercise PH [16, 22-24], with perhaps the exception of elderly individuals (age $>70$ years) where normative data remains limited. However, high quality longitudinal studies on the natural history of exercise $\mathrm{PH}$ are lacking and there remains no proof, to date, that exercise $\mathrm{PH}$ is of prognostic importance. Notwithstanding that exercise $\mathrm{PH}$ is a real pathophysiological entity; current guidelines have remained very cautious and do not support the use of any haemodynamic thresholds to define exercise $\mathrm{PH}$ [14], until more evidence is gathered to validate any proposed new criteria.

In the current issue of the European Respiratory Journal, STAмм et al. [25] provide provocative data from their single centre study on the prognostic relevance of exercise PH in SSc. A total of 72 consecutively eligible SSc patients with a clinical suspicion of $\mathrm{PH}$ (due to exertional dyspnoea and/or reduced diffusing capacity of the lung for carbon monoxide (DLCO) and/or a forced vital capacity (FVC)/DLCO ratio >1.6) underwent diagnostic exercise right heart catheterisation (RHC) with supine incremental cycle ergometry. It was usual clinical practice in the authors' institution to perform exercise haemodynamics in all patients undergoing RHC, unless they were physically unable to exercise. Patients were stratified into three groups according to resting and exercise haemodynamic findings: 1$)$ resting precapillary $\mathrm{PH}$ ( $\mathrm{mPAP} \geqslant 25 \mathrm{mmHg}$ and pulmonary artery wedge pressure (PAWP) $\leqslant 15 \mathrm{mmHg}$ at rest; $\mathrm{n}=17$ ); 2) exercise PH (mPAP $<25 \mathrm{mmHg}$ at rest with $\mathrm{mPAP}>30 \mathrm{mmHg}$ and TPR $>3 \mathrm{WU}$ at peak exercise; $\mathrm{n}=28$ ); and 3) no PH (not fulfilling any of the former criteria; $n=27$ ). Patients with a post-capillary $\mathrm{PH}$ component (resting PAWP $>15 \mathrm{mmHg}$ or exercise PAWP $>20 \mathrm{mmHg}$ ) and those with severe lung function impairment (FVC $<60 \%$ predicted) were excluded. Patients were followed for a median of 33 months and transplant-free survivals of the three groups were compared.

The main finding of the study was that among SSc patients with normal mPAP at rest, the presence of exercise $\mathrm{PH}$, using the recently proposed criteria of $\mathrm{mPAP}>30 \mathrm{mmHg}$ and TPR $>3 \mathrm{WU}$ at peak exercise, was associated with a reduced survival compared to those with normal resting and exercise haemodynamics (no PH group). The estimated 1-, 3- and 5-year transplant-free survival rates were 100\%, $93 \%$ and $82 \%$ in the exercise $\mathrm{PH}$ group versus $100 \%, 93 \%$ and $93 \%$ in the no $\mathrm{PH}$ group ( $\mathrm{p}=0.043$ ). Surprisingly, no survival difference was observed between the exercise $\mathrm{PH}$ and resting precapillary $\mathrm{PH}$ groups. Supporting the concept that progressive pulmonary vascular disease might have accounted for the worse prognosis in the exercise $\mathrm{PH}$ group, four out of the five deaths at follow-up in this group were due to right heart failure versus none in the no PH group. These results imply that exercise $\mathrm{PH}$ in SSc is not a benign disorder and mirror the findings of a previous UK multicentre study, which showed that 19\% of patients with SSc-related exercise PH developed resting PAH at a mean follow-up of 2.3 years [4].

Although the present study by STAmм et al. [25] is the first demonstration that exercise PH in SSc confers prognostic significance and provides external validation of the proposed exercise $\mathrm{PH}$ criteria, there are important caveats. This was a relatively small, retrospective, single centre study and systematic follow-up was not part of the study protocol. Therefore, we have no knowledge of the true rate of conversion to manifest PAH (proven with RHC) in the exercise PH group. The survival curves of the exercise $\mathrm{PH}$ and no $\mathrm{PH}$ groups diverged at a follow-up time when there were only a small number of at-risk subjects remaining, which may limit the robustness of the results. The no $\mathrm{PH}$ group was significantly younger than the exercise PH group, which could have influenced the observed survival difference. The results of this study strictly pertain to a selected population of SSc patients who underwent RHC for clinical suspicion of $\mathrm{PH}$, and are not generalisable to other population groups. Importantly, it is likely that the natural history and outcomes of exercise $\mathrm{PH}$ are disease specific. For example, we do not know whether the same abnormal exercise pulmonary haemodynamic response has different prognostic implications in SSc, chronic thromboembolic disease, lung disease or asymptomatic carriers of a PAH-causing mutation.

The haemodynamic findings of the study warrant some discussion. By definition, the no PH group did not reach $\mathrm{mPAP}>30 \mathrm{mmHg}$ and $\mathrm{TPR}>3 \mathrm{WU}$ at peak exercise. However, when analysed by multipoint mPAP-cardiac output plots, the no PH group displayed unusually steep mPAP-cardiac output slopes with an average slope of $3.7 \mathrm{WU}$. A subject with an $\mathrm{mPAP}$-cardiac output slope of $>3 \mathrm{WU}$ will usually reach exercise $\mathrm{mPAP}>30 \mathrm{mmHg}$ and $\mathrm{TPR}>3 \mathrm{WU}$, unless exercise is curtailed prematurely before peak exercise [26]. Another important observation is that the exercise $\mathrm{PH}$ group displayed a higher median exercise PAWP compared with the no $\mathrm{PH}$ group (16 versus $11 \mathrm{mmHg}$ ), despite comparable resting PAWP values. Occult left heart disease is common in SSc [27] and although patients with an exercise PAWP $>20 \mathrm{mmHg}$ were excluded from the present study, an exercise-induced rise in PAWP contributed, in part, to the abnormal mPAP response seen in the exercise $\mathrm{PH}$ group. This is a salient point since exercise $\mathrm{PH}$ can result from increased pulmonary vascular resistance (due to pulmonary vascular disease) and/or increased 
left atrial pressure (due to left heart disease). This can be especially problematic in SSc where both mechanisms may coexist and contribute to the development of exercise $\mathrm{PH}$.

Although SSc has been the most studied population, exercise haemodynamics are of potential relevance in other at risk groups. Of particular interest are asymptomatic carriers of PAH-causing mutations. Carriers of bone morphogenetic protein receptor type 2 (BMPR2) gene mutation, the most common cause of heritable PAH, have a $20 \%$ lifetime risk of developing PAH [28]. A prospective screening study of asymptomatic BMPR2 mutation carriers has now completed recruitment (DELPHI-2 study; clinicaltrials. gov identifier number: NCT01600898) and will inform on the predictive value of invasive exercise haemodynamics for the future occurrence of $\mathrm{PAH}$ in this population.

Should patients with exercise $\mathrm{PH}$ be offered PAH therapy? Interestingly, targeted PAH treatment was administered to 16 (57\%) patients with exercise $\mathrm{PH}$ in the present study. No significant improvement in 6-min walking distance was observed at 3-month follow-up, and the authors acknowledge that PAH therapy was used strictly off-label at the discretion of the treating physicians. Based on the lack of high-quality efficacy data $[29,30]$, the use of PAH therapy for exercise PH cannot be recommended at present.

STAMm et al. [25] are to be congratulated for executing a study that provides evidence, for the first time, that exercise PH in SSc is of potential prognostic relevance. Clinicians and researchers who believe in the importance of exercise pulmonary haemodynamics have eagerly awaited such studies. In recognition of the ongoing interest and unresolved questions in this field, the European Respiratory Society has formed an expert multidisciplinary task force to evaluate the scientific knowledge and evidence base for exercise pulmonary haemodynamic testing, and to identify priority areas for future research. A particular focus of the task force is to evaluate the methodology of invasive haemodynamic testing, since a uniform testing methodology is a prerequisite for any future definition of exercise $\mathrm{PH}$ and is fundamental for multicentre collaborations, which are likely to be needed to achieve major scientific advancement.

\section{References}

1 Tyndall AJ, Bannert B, Vonk M, et al. Causes and risk factors for death in systemic sclerosis: a study from the EULAR Scleroderma Trials and Research (EUSTAR) database. Ann Rheum Dis 2010; 69: 1809-1815.

2 Avouac J, Airo P, Meune C, et al. Prevalence of pulmonary hypertension in systemic sclerosis in European Caucasians and metaanalysis of 5 studies. J Rheumatol 2010; 37: 2290-2298.

3 Launay D, Sitbon O, Hachulla E, et al. Survival in systemic sclerosis-associated pulmonary arterial hypertension in the modern management era. Ann Rheum Dis 2013; 72: 1940-1946.

4 Condliffe R, Kiely DG, Peacock AJ, et al. Connective tissue disease-associated pulmonary arterial hypertension in the modern treatment era. Am J Respir Crit Care Med 2009; 179: 151-157.

5 Lau EM, Humbert M, Celermajer DS. Early detection of pulmonary arterial hypertension. Nat Rev Cardiol 2015; 12: $143-155$.

6 Humbert M, Gerry Coghlan J, Khanna D. Early detection and management of pulmonary arterial hypertension. Eur Respir Rev 2012; 21: 306-312.

7 Humbert M, Yaici A, de Groote P, et al. Screening for pulmonary arterial hypertension in patients with systemic sclerosis: clinical characteristics at diagnosis and long-term survival. Arthritis Rheum 2011; 63: 3522-3530.

8 Coghlan JG, Denton CP, Grünig E, et al. Evidence-based detection of pulmonary arterial hypertension in systemic sclerosis: the DETECT study. Ann Rheum Dis 2014; 73: 1340-1349.

9 Thakkar V, Nikpour M, Stevens WM, et al. Prospects for improving outcomes in systemic sclerosis-related pulmonary hypertension. Intern Med J 2015; 45: 248-254.

10 Coghlan JG, Bogaard HJ. Exercise pulmonary haemodynamics: a test in search of purpose. Eur Respir J 2016; 47: 1315-1317.

11 Naeije R, Vonk Noordegraaf A, Kovacs G. Exercise-induced pulmonary hypertension: at last! Eur Respir J 2015; 46: 583-586.

12 Naeije R. In defence of exercise stress tests for the diagnosis of pulmonary hypertension. Heart 2011; 97: 94-95.

13 Rubin LJ. Cor pulmonale revisited. J Am Coll Cardiol 2013; 62: 1112-1113.

14 Galiè N, Humbert M, Vachiery JL, et al. 2015 ESC/ERS Guidelines for the diagnosis and treatment of pulmonary hypertension. Eur Respir J 2015; 46: 903-975.

15 Tolle JJ, Waxman AB, Van Horn TL, et al. Exercise-induced pulmonary arterial hypertension. Circulation 2008; 118: 2183-2189.

16 Lau EM, Chemla D, Whyte K, et al. Does exercise pulmonary hypertension exist? Curr Opin Pulm Med 2016; 22: 400-407.

17 Kovacs G, Maier R, Aberer E, et al. Borderline pulmonary arterial pressure is associated with decreased exercise capacity in scleroderma. Am J Respir Crit Care Med 2009; 180: 881-886.

18 Oliveira RK, Waxman AB, Agarwal $\mathrm{M}$, et al. Pulmonary haemodynamics during recovery from maximum incremental cycling exercise. Eur Respir J 2016; 48: 158-167.

19 Badesch DB, Champion HC, Sanchez MA, et al. Diagnosis and assessment of pulmonary arterial hypertension. J Am Coll Cardiol 2009; 54: Suppl., S55-S66.

20 Kovacs G, Berghold A, Scheidl S, et al. Pulmonary arterial pressure during rest and exercise in healthy subjects: a systematic review. Eur Respir J 2009; 34: 888-894.

21 Kovacs G, Avian A, Olschewski H. Proposed new definition of exercise pulmonary hypertension decreases false-positive cases. Eur Respir J 2016; 47: 1270-1273.

22 Herve P, Lau EM, Sitbon O, et al. Criteria for diagnosis of exercise pulmonary hypertension. Eur Respir J 2015; 46: 728-737. 
23 Naeije R, Vanderpool R, Dhakal BP, et al. Exercise-induced pulmonary hypertension: physiological basis and methodological concerns. Am J Respir Crit Care Med 2013; 187: 576-583.

24 Lau EM, Godinas L, Sitbon O, et al. Resting pulmonary artery pressure of 21-24 mmHg predicts abnormal exercise haemodynamics. Eur Respir J 2016; 47: 1436-1444.

25 Stamm A, Saxer S, Lichtblau M, et al. Exercise pulmonary haemodynamics predict outcome in patients with systemic sclerosis. Eur Respir J 2016; 48: 1658-1667.

26 Godinas L, Lau EM, Chemla D, et al. Diagnostic concordance of different criteria for exercise pulmonary hypertension in subjects with normal resting pulmonary artery pressure. Eur Respir J 2016; 48: 254-257.

27 Saggar R, Khanna D, Furst DE, et al. Exercise-induced pulmonary hypertension associated with systemic sclerosis: four distinct entities. Arthritis Rheum 2010; 62: 3741-3750.

28 Girerd B, Montani D, Jaï X, et al. Genetic counselling in a national referral centre for pulmonary hypertension. Eur Respir J 2016; 47: 541-552.

29 Saggar R, Khanna D, Shapiro S, et al. Brief report: effect of ambrisentan treatment on exercise-induced pulmonary hypertension in systemic sclerosis: a prospective single-center, open-label pilot study. Arthritis Rheum 2012; 64: 4072-4077.

30 Kovacs G, Maier R, Aberer E, et al. Pulmonary arterial hypertension therapy may be safe and effective in patients with systemic sclerosis and borderline pulmonary artery pressure. Arthritis Rheum 2012; 64: 1257-1262. 